\title{
Towards Optimal Cooperation and Job Performance: The Impact of Leadership on Role Ambiguity and Role Conflict
}

\author{
Mohammed Al-Malki \\ School of Economics, Central China Normal University, Wuhan, China
}

\begin{abstract}
The paper explores the ways to achieve superior job performance and cooperation among employees. The conceptual study suggests that leadership styles have influence on role conflict and role ambiguity, which in turn impact job performance and cooperation. The research paper builds on the theory of leadership and contributes to the leadershipperformance body of work. The importance of role stressors which include role ambiguity and role stressors is considered to be critical since understanding these role stressors enables policymakers and leaders to take necessary measures which can be used to increase the job performance and cooperation among employees. The current research proposes the conceptual framework which can be used to analyse the influence of different types of leaders in response to role stressors, such as role conflict and role ambiguity which are directly related to job performance and cooperation.
\end{abstract}

Keywords: Transformational leadership, Role ambiguity, Role conflict, Job performance, Cooperation

\section{Introduction}

Leaders are reported to influence the organizational effectiveness by impacting their followers. In other words, leaders significantly influence employees within the organization. Particularly, transactional leaders use reward based system in order to motivate their workers. However, using reward based systems in order to motivate the employees is reported to have short term impact. Compared to transactional leadership, transformational leadership style is believed to be the style of leadership which improves the engagement of employees (Keegan, 2004; Bass, 1990; Pearce, 1981). Transformational leadership enables the employees to see themselves as the part of a large group, rather than being isolated individuals. When employees and followers consider themselves as the members of the large group and collective organization, they feel more sense of responsibility for the achievement of organizational goals. Transformational leaders are believed to motivate their followers through their strong inspiring visions which will help their followers to overcome their selfinterest. Leaders who are more likely to inspire others and motivate their fellows are more likely to have high level of enthusiasm and energy. Leaders are believed to energize their team members in order to achieve common goals of the company thus by increasing the performance of each team member. Most of the leaders fail in inspiring their followers being strongly focused on accomplishment of specific tasks (Russo, 2012). However, this is considered as a huge mistake. The laissez-faire leader provides their subordinates with all necessary materials but they do not take participation in decision-making process. They are reported to take part in important question and answer sessions (Mohammed, 2016). Moreover, laissez-faire leaders are likely to avoid giving feedback to their subordinates since subordinates are given full freedom and authority.

Today, most of the organizations rely on the formulation and establishment of good teamwork process in order to improve the organizational effectiveness and performance of the employees. In this regard, the role of leaders is considered to be of critical importance. One of the efficient ways of formulating high performing teams is to understand the individual preferences of the team members and to understand their expectations. Moreover, each member of the team should be informed about their specific roles and responsibilities. In short, expectations of top level managers should be clearly identified and communicated properly to employees and subordinates (Van, 1981). Therefore, the roles and position of leaders are regarded to be critical as they have close contact with their subordinates. Furthermore, the subordinates and 
members of the team are strongly influenced by the attitude and behaviour of leaders as well. Research which studies the importance of the influence of different types of leadership styles on measuring the employee job performance and cooperation among employees show that the influence of leaders is found to be significant in each context. Precisely, the leaders are expected to directly impact on the role stressors of the job which is reported to influence job performance and cooperation among the employees (Simon, 2014). The main types of role stressors identified and discussed in the literature can be considered as role ambiguity and role conflict. In this regard it is worth to mention several numbers of papers which have analysed the influence of role stressors and role ambiguity on organizational commitment and team performance.

The research conducted by Shepherd and Fine (1994) has revealed the influence of role stressors including role ambiguity and role conflict on salesperson job performance and satisfaction. Precisely, the high level of role stressors is found to influence negatively on job performance, by decreasing the effectiveness of salespeople. The research conducted by Peterson (1995) found another type of role stressors such as role overload alongside role ambiguity and role conflict. Leaders are reported to influence the organizational effectiveness by means of impacting on their followers. In other words, leaders significantly influence employees within the organization. Particularly, transactional leaders use reward based system in order to motivate their workers. However, using reward based systems in order to motivate the employees is reported to have short-term impact (Mumford, 2000). Compared to transactional leadership, transformational leadership style is believed to be the style of leadership which improves the engagement of employees. The transformational leadership enables the employees to see themselves as the part of a large group, rather than being isolated individuals. When employees and followers consider themselves as the members of the large group and collective organization, they feel more sense of responsibility for the achievement of organizational goals. Transformational leaders are believed to motivate their followers through their strong inspiring visions which will help their followers to overcome their selfinterest. Several studies found that role stressors including role ambiguity and role conflict were found as the main source of job dissatisfaction (Koustelios, 2004). Moreover, studies conducted by Hill (2015) found that role conflict and role ambiguity are found to decrease job performance of the employees resulting in job dissatisfaction.

\section{Leadership styles and their effects}

\subsection{Passive laissez-faire leadership}

This type of leadership is mainly based on the trust. Laissez-faire type of leadership is mainly described as the process of the leadership which abdicates the responsibilities and avoids decision making. In other words, laissez-faire give their decision-making authority to their subordinates and employees (Bass, 2006). The literature suggests that it is very difficult to support this type of leadership if the members of the group or subordinates of the leader are experienced or experts of their own specific fields. Research in the field of leadership relates the cases of laissez-faire leadership with negative organizational outcomes including employee demotivation and stress. This type of leadership is also considered as the passive type of leadership which is characterized as non-strategic and complete opposite of transformational and transactional leadership (Yang, 2015). The decreasing job performance of the employees and higher level of job dissatisfaction is mainly related with low involvement of the current type of leaders with daily operations of the organization (House, 1972).

\subsection{Transformational Leadership}

The concept of transformational leadership has attracted the attention of the academics and experts for the last 20 years being one of the mostly discussed topics in the field of leadership. Bass (1990) introduced the "full range model of leadership", which is considered as the most popular and well-known theory in the modern world. According to this theory, there are three important dimensions of the leadership which start from laissez-faire leadership (also known as absence of leadership) followed by transactional leadership and transformational leadership.

Transformational leadership is considered as the basis of "full range model of leadership" represented by Bass (1990). As its name suggests, transformational leadership involves the transformation of employees to higher levels of achievement through proper motivation and appraisal by encouraging them to reach their individual goals. The process of sharing common vision in the case of transformational leadership is worth mentioning in this regard. Therefore, under the control of transformational leaders, under their shared vision and motivation, employees and team members are expected to reach the target goals and often they exceed the expectation of the upper-level management. In this regard, it is important to mention four important components of the transformational leaders. 
One of them is the individual consideration (Mumford, 2000). The more clear examples of the current function can be explained in cases when leaders provide necessary advice and support their followers by giving them necessary instructions regarding accomplishment of particular or specified task. Another important element of individual considerations is that team members are given the learning opportunity which is known as the crucial part of successful teamwork. Besides individual considerations, transformational leaders are also characterized and distinguished by their role of "intellectual stimulation". In other words, subordinates are given a chance and encouraged to take different looks into different problems from various angles in the purpose of widening their outlook and learning new knowledge or particular information which might be of use for the successful completion of the project. This process develops the intellectual ability of the learners and team members by providing them with a better chance to develop their creative thinking (Bass, 2006). The thinking process, mainly creative thinking is an essential part of the teamwork since mainly the subordinates with creative and innovative ideas will lead to the changes that might be beneficial for all team members.

Transformational leadership is also popular for its element which can be regarded as inspirational motivation. The inspirational motivation is considered to be of particular importance for the member of the group since the engagement of each team member towards the achievement of the common goal and providing them motivation are the critical factors of successful cooperation of team member and completion of the project (Chen, 2005).

The importance of the inspirational motivation can be critical since it may result in positive changes in the environment of the teamwork. When team members feel inspired, they are more likely to accomplish their tasks with stronger motivation and responsibility so that even if they encounter some challenges and difficulties they never give up given that the strong motivation and inspiration provided by the leader. The last but not least, idealized influence is considered as the most critical element of transformational leadership since in this case the leaders become a role model for their subordinates and earn their trust and loyalty (Mumford, 2000). Therefore, idealized influence is given higher priority among all other types of transformational leadership development.

\subsection{Transactional leadership}

Alongside transformational leadership, transactional leadership has also achieved a significant importance and widely discussed in the leadership sphere. Transactional leadership is described as the type of leadership where the leader's exchange in this regard gives reward or punishment in response to accomplishment of the predefined goal by the subordinate. In other words, leader and the follower or in the case of the teamwork, the member of the team agree on accomplishment of the specific tasks which will be clearly defined and provided for the subordinates and in response they will be offered some form of reward in the form of remuneration. In this case, employees agree on fulfilling the responsibilities provided by the leader and they try in often times to do their best in order to achieve the reward (Russo, 2012). In cases, when predefined objectives are not met completely, subordinated will be given punishment. Most of the papers which analysed and discussed the case of transactional leaders and their influence on employee motivation found out that while agreeing on the accomplishment of the certain tasks, there will be mutual trust between team member and leaders. In other words, it has been reported that team members can be extrinsically motivated when leaders are transactional whereas it is common for many team members to be intrinsically motivated in the case of the transformational leaders (Pearce, 2009). It is worth to mention that transactional leaders often provide salaries and bonuses as a reward for their followers in exchange for the accomplished work since these are considered as one of the crucial factors that motivate people.

\subsection{Task-focused}

Various types of task-oriented leadership have been identified in the literature including transactional leadership, directive leadership and spanning of boundary. Transactional leadership is often characterized as the type of leader who motivates and rewards their followers given their high performance of tasks completed. Precisely, the nature of relationship between leaders and followers can be explained by the contract where the followers are given their duties and upon completion of their responsibilities, they will receive their rewards (Avolio \& Bass, 2000). Directive leadership is described as the type of task focused leadership where leaders are differentiated by their role of providing necessary direction which will simplify the process of fulfilling certain tasks without ambiguity (Gottfried, 2011). The formulation of directive leadership is strongly related to hierarchical organizational structures where specific tasks will be given to the people under control. Obviously, followers are required to listen to the commands of leaders who have high power of decision making. 
However, in certain cases, there may be need for the members of the team to make quick decision; therefore certain decisions of lower priority can be made by the followers themselves. Another important function of task-focused leaders is spanning of a boundary where they can work closely with other members of the team in order to provide them necessary instructions so that projected assignments will be finished on time. Task-focused leadership is quite critical for the successful completion of group projects, therefore, the functions of task focused leadership should be accomplished properly (Dragoni, 2005). Precisely, directive relationship function is mainly critical in the beginning phase of the team work since each member should be sufficiently about their roles and responsibilities. The allocation of responsibilities among the team members and providing necessary direction is considered as critical importance of fulfilling the tasks on time.

\subsection{Person-focused leadership}

Person-focused leadership is represented by different factors such as transformational leadership, consideration, empowerment and motivation. Person-focused leadership is found to be significant in the context of teamwork, particularly. One of the characteristics of person focused leadership is transformational leadership (Howell, 1989). Transformational leadership is similar to the charismatic leaders. In other words, transformational leaders are known for sharing the vision which will motivate their subordinates towards the achievement of the common team work. When transformational leaders share their vision with subordinates, followers and team members are more likely to perform beyond expectations (Mohammed, 2016). Another important function of person-focused leadership is consideration which mainly deals with the fact that leaders consider and pay attention to the needs and suggestions of their followers in order to ensure the mutual trust in the teamwork. Empowerment function of the leaders refers to the self-management of the followers which is considered as crucial as motivation (Mach, 2010). Motivation is regarded as the continuation of the ongoing effort which is undertaken by the team even at times of difficulty. Generally, person-focused leadership becomes significant when there is a strong need for team motivation and inspiration.

\section{Impact of roles on performance}

The literature claims that the dysfunctions in most of the organisations and conflicts in the teamwork mainly result of the role ambiguity and role conflict. The classical organizational theory suggests that principal chief of command and the directions provided by the top-level managers have important implications in order to have a clear picture of the underlying factors, which cause role ambiguity and role conflict (Keegan, 2004). However, there is a lack of empirical studies, which study the importance and potential consequences of role conflict and role ambiguity on performance of the employees in the case of the teamwork. Chain of command principle theory suggests that the instructions and guidelines provided for the employees and subordinates by the top level managers should be clear and concise enough in order to prevent the causes of the conflicts and misunderstandings which might arise due to the improper allocation of duties and responsibilities (Datnow, 2001). The principle of unity command theory suggests that there should be only one team leader or superior who provides and gives the basic guidelines of the required tasks to be done. The idea of having one leader and manager is considered as an advantage of the bureaucratic type of organizational structure where each individual or group member will rely and work under the supervision of one individual whereas the reliance on the orders of more than one individual may cause role conflicts and ambiguities.

\subsection{Role conflicts on performance}

According to the role theory, when individuals experience inconsistent behaviour, which is considered as one form of role conflict, they are more likely to be dissatisfied and feel more stressed if their expectations did not conflict (Arami, 2016). Thus, role conflict is considered because of the violating the principles of two prominent theories. Therefore, productivity and efficiency of the employees are likely to decrease. As it is clear from the concept of organizational structure, top managers or people with high level of authority and hierarchy should make it clear for the employees what they are expected to accomplish and their certain duties. Otherwise, employees may face difficulty in terms of deciding what they should do exactly, what kind of decisions they are required to make, in these cases, they are more likely to rely on their own judgement, which will increase the chances of occurrence of role conflict. 


\subsection{Role ambiguity on performance}

Role ambiguity suggests that due to the lack of necessary information available, team members and employees tend to make decisions by themselves, which is likely to increase the chances of role coping in the purpose of feeling less stressed and dissatisfied (Mohammed, (2016). Therefore, based on the role theory it can be mentioned that role ambiguity is supposed to increase the chances of becoming dissatisfied, feeling more stressed and increasing the levels of anxiety.

\subsection{Impacts on cooperation}

Role ambiguity and role conflict is reported to show negative influence on cooperation. In other words, because of the influence of role conflict and role ambiguity employees are not likely to be engaged in good practices of cooperation, which is considered critical for the successful operation of the company (Dubinsky, 1995).

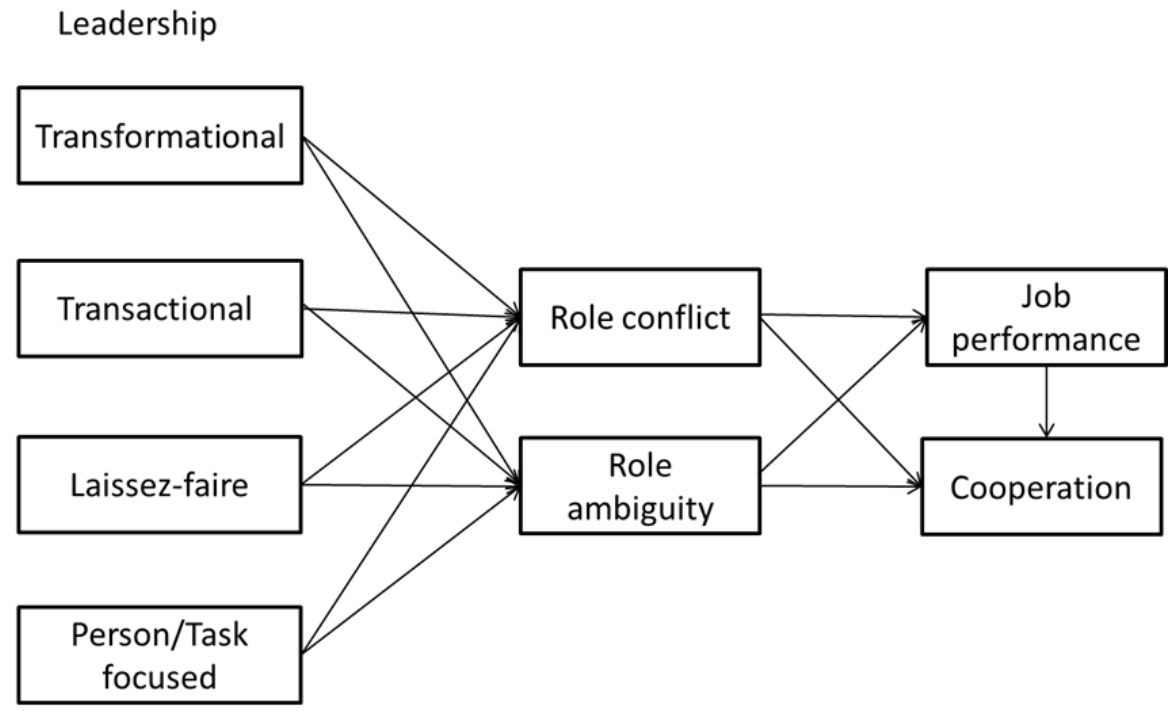

Figure 1: Research model

H1. Transformational leadership has a positive influence in resolving role conflict

Transformational leadership significantly influences the behaviour of team members by sharing their visions and motivating everyone to follow the same vision ( Pearce, 2009). As a result, employees are more likely to accomplish their tasks beyond the expectations. Transformational leaders are more likely to stress the role of each member of the group that will enable to prevent the cases of role conflict.

H2. Transformational leadership has a positive influence in resolving role ambiguity

Transformational leaders provide clear and concise the instruction for each team member so that team members will not have any misunderstanding and conflicts regarding their roles (Barrow, 1977). Therefore, transformational leaders are likely to prevent the cases of role ambiguity.

H3. Transactional leadership has a positive influence in resolving role conflict

Transactional leader motivates the employees by providing the different types of rewards. Transactional leader pays specific attention to the role and responsibility of each subordinate since it is crucial to clarify the role of each team member in order to prevent the cases of role conflict.

H4. Transactional leadership has a positive influence in resolving role ambiguity

Transactional leaders sign contract between the employee and leader regarding the importance and requirements of specific tasks which should be accomplished within the specific period of time. (Mach, 2010), As a result, each employee will have clear understanding of what he or she is expected to accomplish. This is crucial for preventing the cases of the conflicts.

H5. Laissez-faire has a positive influence on instigating role conflict

Due to the passive role of leadership in laissez-faire, leaders are not actively involved in resolving the problems of subordinates. It indicates that employees are given full authority to make necessary decisions (Van, 1981). However, it can lead to the arousal of conflicts, precisely role conflicts among the employees. Therefore, laissez-faire is found to have a 
negative influence in resolving the role conflict.

H6. Laissez-faire has a positive influence on instigating role ambiguity

Laissez-faire leadership is considered to be effective only when subordinates are experienced in their area of competence (Marginson, 2005). However, it may turn out that some subordinates may not know exactly what they are expected to accomplish which can lead to role ambiguity.

H9. Person/task focused leadership has a positive influence in resolving the role ambiguity

Person/task focused leadership focuses on the importance of critical tasks that should be accomplished by subordinates (Van, 1981). Therefore, person/task focused leadership takes individual approach to each subordinate and explains their duties in detail which is quite critical in resolving role ambiguity.

H10. Person/task focused leadership has a positive influence in resolving the role conflict

Employees are clearly instructed and informed about what they are expected to accomplish. Therefore, it can be mentioned that subordinates under the control of task-focused leader are less likely to be involved in role conflict.

H11. Resolving role conflict has a positive influence in increasing job performance

Employees and subordinates who are aware of their required tasks are less likely to be involved in role conflicts (House, 1972). Therefore, they accomplish their responsibilities with high level of responsibility which is crucial in increasing their job performance.

H12. Resolving ambiguity has a positive influence in increasing the job performance

The clear instructions and guidelines provided for the subordinate are less likely to raise the questions in terms of the responsibility and duties of subordinates (Dubinsky, 1995). Therefore, low levels of ambiguity are positively associated with high level of job performance.

H13. Resolving conflict has a positive influence in increasing the cooperation

The subordinates are more likely to have close cooperation with each other if they do not have any role conflicts (Russo, 2012). The importance of leaders is considered to be crucial in resolving different types of role conflicts.

H14. Resolving role ambiguity has a positive influence in increasing the cooperation Lower rates of role ambiguity are expected to be positively related with increased cooperation (Marginson, 2005). Employees and subordinates who have clear understanding of their role are more likely to show high levels of cooperation with other team members

H15. Increased job performance has a positive influence on job cooperation

The current research proposed that the increased job performance has a positive relationship with job cooperation (Keegan, 2004). Employees and subordinates who show high levels of job performance are more likely to be engaged in closer cooperation with other team members.

\section{Discussion}

The proposed findings of the current study are believed to provide some practical and useful suggestions for policymakers and managers. The study proposes conceptual framework, which may be useful to understand the influence of different types of leadership including transformational, transactional, laissez-faire and person/task focused. It is important for the organizations to understand the consequences of role ambiguity and role conflict, which is strongly related to job performance (Samuel, 2015). Understanding the influence of different types of leaders on performance of team members is considered critical as it is directly related with the job performance. Role conflict and role ambiguity is found to arise from different sources and most of the sources are explained by the unclear orders, guidelines and tasks provided by supervisors, which are likely to result in decreasing efficiency of job performance. Most of the papers, which investigated the relationship between role ambiguity and role conflict, found out that employees who show high level of role ambiguity are more likely to report decreasing rates of their job performance. It is important for the team leaders to understand the different types of leadership styles since the behaviour of team members and subordinates is going to be influenced by the behaviour of leader.

\section{Conclusion and future studies}

Leadership is considered as a key issue in many organizations and effective practices of leadership are reported to have a positive relationship with increased and improved organizational effectiveness and performance (Skogstad, 2007). The number of their characteristics, which they may find to vary in terms of guiding, motivating and allocating the tasks to 
their subordinates, may have critical impacts on the efficiency of teamwork process and efficiency of each group member. Leaders are good at inspiring the action and vision, which can positively influence and accelerate the process of exchange of ideas and knowledge (Dubinsky, 1995). As a result, members of the team start feeling more responsible towards their job and duties. Thus, it can be mentioned that increased job performance is critical in order to formulate the strong ties among the different member of the group. Most of the investigations carried out in the sphere of the factors, which determine the influence of various factors on team performance, mentioned that role conflict and role ambiguity is considered as the most two important factors which are likely to result in not so favourable personal outcomes. The current research is going to collect the data by utilizing multifactor leadership questionnaire. Multifactor leadership questionnaire is regarded as the most popular and common scale which is used to measure the significance of the transactional, transformational and passive leadership styles.

\section{References}

- Arami, M., (2016) Comparison of leadership style of male and female managers in Kuwait: An empirical investigation. Journal of International Business Research and Marketing. Volume 1, Issue 2, January 2016, Pages 37 40 .

- Barrow, J. C. (1977). The variables of leadership: A review and conceptual framework. Academy of Management Review, 2(2), 231-251, CrossRef, CrossRef

- $\quad$ Bass, B. M., \& Riggio, R. E. (2006). Transformational leadership. Mahwah, NJ: Erlbaum

- Chen, H., Beck, S., \& Amos, L. (2005). Leadership styles and nursing faculty job satisfaction in Taiwan. Journal of Nursing Scholarship, 37, 374-380, CrossRef

- Datnow, A., \& Castellano, M. E. (2001). Managing and guiding school reform: Leadership in success for all schools. Educational Administration Quarterly, 37(2), 219-249, $\underline{\text { CrossRef }}$

- Dragoni, L. (2005). Understanding the emergence of state goal orientation in organizational units: The role of leadership and multilevel climate perceptions. Journal of Applied Psychology, 90, 1084-1095, CrossRef

- Dubinsky, A. J., Yammarino, F. J., Jolson, M. A., \& Spangler, W. D. (1995). Transformational leadership: An initial investigation in sales management. Journal of Personal Selling \& Sales Management, 15(2), 17-31.

- $\quad$ Gottfried, A. E., Gottfried, A. W., Reichard, R. J., Guerin, D. W., Oliver, P. H., \& Riggio, R. E. (2011). Motivational roots of leadership: A longitudinal study from childhood through adulthood. The Leadership Quarterly, 22(3), 510519, $\underline{\text { CrossRef }}$

- Hill, K., Chênevert, D., \& Poitras, J. (2015). Changes in relationship conflict as a mediator of the longitudinal relationship between changes in role ambiguity and turnover intentions. International Journal of Conflict Management, 26(1), 44-67, CrossRef

- House, R. J., \& Rizzo, J. R. (1972). Role conflict and ambiguity as critical variables in a model of organizational behavior. Organizational behavior and human performance, 7(3), 467-505, CrossRef

- Howell, J. M., \& Avolio, B. J. (1989). Transformational versus transactional leaders: How they impart innovation, risk-taking, organizational structure and performance. Paper, Academy of Management, Washington, DC.

- Howell, J. M., \& Frost, P. J. (1989). A laboratory study of charismatic leadership. Organizational behavior and human decision processes, 43(2), 243-269. Chicago, $\underline{\text { CrossRef }}$

- Jago, A. G. (1982). Leadership: Perspectives in theory and research. Management science, 28(3), 315-336, CrossRef

- Keegan, A. E., \& Den Hartog, D. N. (2004). Transformational leadership in a project-based environment: a comparative study of the leadership styles of project managers and line managers. International journal of project management, 22(8), 609-617, CrossRef

- Koustelios, A., Theodorakis, N., \& Goulimaris, D. (2004). Role ambiguity, role conflict and job satisfaction among physical education teachers in Greece. International Journal of Educational Management, 18(2), 87-92, CrossRef

- Mach, M., Dolan, S. and Tzafrir, S. (2010), “The differential effect of team members' trust on team performance: the mediation role of team cohesion", Journal of Occupational and Organizational Psychology, Vol. 83 No. 3, pp. 771-94, CrossRef

- Marginson, D., \& Ogden, S. (2005). Coping with ambiguity through the budget: the positive effects of budgetary targets on managers' budgeting behaviours. Accounting, Organizations and Society, 30(5), 435-456, CrossRef

- Miles, R. (1976). A Comparison of the Relative Impacts of Role Perceptions of Ambiguity and Conflict by Role. The Academy of Management Journal, 19(1), 25-35, CrossRef 
- $\quad$ Mumford, M., Zaccaro, S. J., Johnson, J. F., Diana, M., Gilbert, J. A., \& Threlfall, K. (2000). Patterns of leader characteristics: Implications for performance and development. The Leadership Quarterly, 11(1), 115-133, CrossRef

- Pearce, C.L., Manz, C.C. and Sims, H.P. (2009), "Is shared leadership the key to team success?", Organizational Dynamics, Vol. 38 No. 3, pp. 234-8, CrossRef

- Pearce, J. L. (1981). Bringing some clarity to role ambiguity research. Academy of Management Review, 6(4), 665674, CrossRef, CrossRef

- $\quad$ Peterson, M. F., Smith, P. B., Akande, A., Ayestaran, S., Bochner, S., Callan, V., ... \& Hofmann, K. (1995). Role conflict, ambiguity, and overload: A 21-nation study. Academy of Management Journal, 38(2), 429-452, CrossRef

- Pfeffer, J. (1977). The ambiguity of leadership. Academy of management review, 2(1), 104-112, CrossRef, CrossRef

- Russo, M. (2012), "Diversity in goal orientation, team performance, and internal team environment", Equality, Diversity and Inclusion: An International Journal, Vol. 31 No. 2, pp. 124-43, CrossRef

- Samuel Sejjaaka, Rachel Mindra, Isa Nsereko (2015) Leadership Traits and Business Sustainability in Ugandan SMEs: A Qualitative Analysis. International Journal of Management Science and Business Administration. Volume 1, Issue 6, May 2015, Pages 42-57, CrossRef

- Shepherd, C. D., \& Fine, L. M. (1994). Scaling and measurement: Role conflict and role ambiguity reconsidered. Journal of Personal Selling \& Sales Management, 14(2), 57-65.

- Simon C.H. Chan, Wai-ming Mak, (2014) "The impact of servant leadership and subordinates' organizational tenure on trust in leader and attitudes", Personnel Review, Vol. 43 Iss: 2, pp.272 - 287, CrossRef

- Skogstad, A., Einarsen, S., Torsheim, T., Aasland, M. S., \& Hetland, H. (2007). The destructiveness of laissez-faire leadership behavior. Journal of occupational health psychology, 12(1), 80, CrossRef

- Stajkovic, A. D., \& Luthans, F. (1998). Self-efficacy and work-related performance: A meta-analysis. Psychological Bulletin, 124, 240-261, CrossRef

- Teas, R. K. (1983). Supervisory behavior, role stress, and the job satisfaction of industrial salespeople. Journal of marketing research, 84-91, CrossRef

- Van Sell, M., Brief, A. P., \& Schuler, R. S. (1981). Role conflict and role ambiguity: Integration of the literature and directions for future research. Human relations, 34(1), 43-71, $\underline{\text { CrossRef }}$

- Yang, I. (2015). Positive effects of laissez-faire leadership: conceptual exploration. Journal of Management Development, 34(10), 1246-1261, CrossRef 